\title{
Effect on Development of Proportional Reasoning Skill of Physical Experience and Cognitive Abilities Associated with Prefrontal Lobe Activity
}

\author{
Yong-Ju Kwon, ${ }^{1}$ Anton E. Lawson, ${ }^{2}$ Wan-Ho Chung, ${ }^{3}$ Young-Shin Kim ${ }^{3}$ \\ ${ }^{1}$ Center for Innovative Teaching \& Learning, Pohang University of Science \& Technology, \\ Pohang, Kyungbuk 790-784 Korea \\ ${ }^{2}$ Department of Biology, Arizona State University, Tempe, Arizona 85287 \\ ${ }^{3}$ Department of Biology Education, Korea National University of Education, Cheongwon, \\ Chungbuk 363-791 Korea
}

Received 14 July 1999; accepted 26 July 2000

\begin{abstract}
The present study tested the hypothesis that maturing prefrontal lobes play a role in the development of proportional reasoning skill because the prefrontal lobes are involved in the inhibition of task-irrelevant information and the representation of task-relevant information. The hypothesis that reasoning development is in part dependent upon physical experience was also tested. Students (all males) who failed to solve a diagnostic proportions task were administered several tests of prefrontal lobe functions. The students were then randomly assigned to manipulative or verbal tutoring groups. Both groups received a series of individual testing, tutoring and testing sessions on proportional reasoning. As predicted, performance on the prefrontal lobe tasks (measures of inhibiting ability, planning ability, dissembedding ability, and working memory capacity) significantly predicted performance on proportional reasoning tasks following tutoring. Students' computational skills were not a significant predictor. Also, the manipulative group's proportional reasoning performance was significantly higher than that of the verbal tutoring group. Therefore, the present results provide support for the hypothesis that maturing prefrontal lobes and physical experience play roles in the development of proportional reasoning skill.@ $2000 \mathrm{John}$ Wiley \& Sons, Inc. J Res Sci Teach 37: 1171-1182, 2000
\end{abstract}

\section{Introduction}

According to Epstein (1974a, 1974b, 1978, 1986), Hudspeth and Pribram (1990), Thatcher (1991) and Thatcher, Walker, and Giudice (1987), brain growth during childhood and

\footnotetext{
Correspondence to: A.E. Lawson

Contract grant sponsors: National Science Foundation and Korea Science and Engineering Foundation; Contract grant number: DOE 9453610 and KOSEF-1999-2-5001-003-3
} 
adolescence occurs in terms of plateaus and spurts. Based on this research, Kwon and Lawson (2000) predicted and found students' performance on some measures of prefrontal lobe activity did not increase from age 13 to 14 (when brain growth is presumably in a plateau period) and then increased from age 14 to 16 (when brain growth presumably is in a spurt period).

Kwon and Lawson (2000) also predicted and found a similar age-wise pattern in scientific reasoning ability and in students' ability to learn science concepts. They argued that the maturing prefrontal lobes play a role (along with physical and social experience) in the development of scientific reasoning ability and in the acquisition of science concepts because the frontal lobes are involved in the inhibition of task-irrelevant information and in the representation of task-relevant information, skills needed for both reasoning and concept acquisition. Nevertheless, the link between prefrontal lobe maturation and scientific reasoning found by Kwon and Lawson was correlational in nature. Therefore, the primary purpose of the present study is to determine whether or not such a link can be found experimentally.

More specifically, the present study attempts to teach a sample of students (all males) aged 13 to 15 how to solve tasks using proportional reasoning - an aspect of scientific reasoningduring a series of four 30-minute individual tutoring sessions. Students' ability to profit from this individual instruction is compared to their performance on measures of prefrontal lobe activity. Based on brain maturation theory, students with relatively poor performance on the measures of prefrontal lobe activity are predicted to profit less.

Bruner (1965) argued that humans construct models of their world through three information processing systems (i.e., action, imagery, and language). Further, Stein and Meredith (1993) found that the combined sensory pathways of visual, auditory, and somatosensory (touch) were more effective in detecting rates and reacting times of neuronal signals than uni- or bidimensional pathways (e.g., visual, auditory, somatosensory, visual-auditory, visual-somatosensory, and auditory-somatosensory). Consequently, learning environments that incorporate sights, sounds, and touches should be more effective than those lacking one or more inputs. Indeed, several related studies (cf., Druyan, 1997; Lawson, 1986; Lawson \& Wollman, 1980) have shown that kinesthetic feedback or manipulative instruction is more effective than only verbal feedback in promoting children's cognitive conflict and conceptual change within proportional reasoning problems.

Therefore, a secondary objective of the study is to compare the effectiveness of verbal tutoring with tutoring that includes the use of manipulatives. Based on Bruner's view, results of previously cited research, and developmental theory, which claims that intellectual development is in part dependent upon physical experience (e.g., Inhelder \& Piaget, 1958, Chap. 18), use of the manipulatives is expected to produce greater gains regardless of the level of prefrontal lobe activity.

\section{Methodology}

\section{Subjects}

Fifty-six (56) male students who did not use a proportional reasoning strategy on the diagnostic Pouring Water Task (Suarez \& Rhonheimer, 1974; Lawson, 1978) were selected from a population of 126 males enrolled in the eighth grade of a Korean junior high school. The school was located in a university town of approximately 20,000 people. Subjects ranged in age from 13.08 to 15.17 years, mean age $=13.93$ years, $\mathrm{SD}=0.48$. 


\section{Design}

Subjects were administered a series of tasks previously linked to prefrontal lobe activity manifesting itself in specific cognitive abilities (i.e, inhibiting ability as measured by the Wisconsin Card Sorting Test-WCST, planning ability as measured by the Tower of London task-TOLT, disembedding ability as measured by the Group Embedded Figure Test-GEFT, and mental capacity as measured by the Figural Intersection Test-FIT). Subjects were also administerd a test of computational skills associated with solving ratio and proportion problems.

Subjects were then randomly assigned to a manipulative or a verbal tutoring group. Subjects in each group participated in a series of individual tutoring and testing sessions designed to teach proportional reasoning. Following the instruction, subjects were administered a series of eight proportional reasoning items. Correlation, regression, and $t$-tests were used to investigate statistical relationship(s) among the dependent variable (i.e., performance on the 8 proportional reasoning items) and the independent variables (i.e., performance on the WCST, TOLT, GEFT, FIT, age and computational skill). A $t$-test was used to investigate differences between the manipulative and verbal groups on the eight proportional reasoning items.

\section{Instruments}

Inhibiting Ability. Inhibiting ability was measured by the Wisconsin Card Sorting Test (Heaton et al., 1993). This test consists of four stimulus cards and 128 response cards. The first stimulus card shows one red triangle. The second shows two green stars. The third shows three yellow crosses. And the fourth shows four blue circles. The 128 response cards have different shapes (crosses, circles, triangles, or stars), colors (red, yellow, blue, or green) and number of figures (one, two, three, or four). The subject is given the 128 response cards and asked to match each card to one of the four stimulus cards. After each attempted match, the subject is told whether the match is correct or incorrect, but not told the matching principle (i.e., match by color, match by shape, match by number). More specifically, the first matching principle was match by color. All other attempted matches were called incorrect.

Once the subject made ten consecutive correct color matches, the matching principle was secretly shifted to shape. If the subject continued to incorrectly match by color in spite of negative feedback from the interviewer, he/she is said to have committed a perseveration error (i.e., an incorrect response in card sorting in the face of negative feedback). After ten consecutive correct responses to shape, the principle was shifted to number and then back to color. This procedure continued until the subject successfully completed six matching categories or until all 128 cards had been used.

As this test was quite time-consuming, five interviewers were used to administer the test. Interviewer training included verbal explanations and practical examples on presenting the test directions, on recording student responses, on giving feedback, and on making appropriate category shifts. The training session lasted about 2 hours. Inter-rater reliability of .93 was based on records of sample responses.

Scoring. The number of perseveration errors for each category were summed to obtain a total number for each subject. Data analyses were then run using these numbers; however, note that inhibiting ability is inversely correlated with the number of perseveration errors. In other words, subjects who make fewer perseveration errors are assumed to have more inhibiting ability. 
Planning Ability. Planning ability was assessed by the Tower of London Test. The test requires planning in terms of means-ends analysis to successively solve a set of increasingly difficult tasks (Krikorian, Bartok, \& Gay, 1994; Shallice, 1982). To solve each task, subjects must plan and execute a series of moves with success being defined in terms of task completion within a minimum number of moves. Test materials consist of a board with three vertical wooden sticks of varying heights and three moveable balls. The balls, colored red, green, and blue, can be slid up and down the sticks. The first stick can hold all three balls. The second stick can hold two balls. And the third stick holds just one ball.

From the initial ball positions, the subject is asked to move one ball at a time from stick to stick, in a prescribed number of moves to achieve a certain predetermined goal (e.g., order the balls, green over blue over red on the long stick in five moves). The test requires one to plan a series of sub-goals as one must not only anticipate and visualize the end goal, but each step to that goal must also be mapped in the proper sequence.

Krikorian et al. (1994) developed a set of tasks appropriate for use in grades 1-8. The Krikorian et al. test was modified to include five additional tasks of increasing difficulty for a total of 12 tasks, two of which were practice. Each subject was tested individually by one of five trained interviewers. Training included verbal explanations and practice on presenting test directions, on recording student responses, on checking time limits, and on giving feedback. The training session took about 2 hours. Inter-rater reliability was .95 for a sample of responses.

Scoring. The easiest of the scored tasks required four moves and the most difficult required seven. Three trials were allowed for each task. Subjects were given $1 \mathrm{~min}$ to reach the goal position per trial.

Three points were awarded if the goal position was achieved in the prescribed number of moves and within the time limit on the first trial. Two points were awarded for a successful performance on the second trial. And one point was awarded for a successful performance on the third trial. If a subject failed all three trials, a score of 0 was awarded. A subject's total score was the sum of points earned on all 10 tasks. Thus a maximum of 30 points was possible. In a pilot test of 30 9th-grade students, a Cronbach's reliability coefficient of .61 was obtained.

Disembedding Ability. Disembedding ability was assessed by use of the Group Embedded Figures Test (Dumsha, Minard, \& McWilliams, 1973; Thompson, Pitts, \& Gipe, 1983; Witkin, Moore, Goodenough, \& Cox, 1977; Witkin, Oltman, Raskin, \& Karp, 1971). The test requires subjects to locate and outline simple figures concealed in complex and potentially misleading backgrounds. Disembedding ability improves with age during childhood and adolescence, but one's standing among peers remains relatively stable across age (Witkin et al. 1971, 1977).

The Korean version of the Group Embedded Figures Test used in the present study consists of 16 figures in each of two sections (Jeon \& Jang, 1995). Students were given $10 \mathrm{~min}$ for each section. Ahn (1995) reported a Cronbach's reliability coefficient of .70 when the test was used with a sample of Korean secondary students similar to those in the present study.

Mental Capacity. Mental capacity is defined by Pascual-Leone and Smith (1969) as the size of one's central computing space or working memory. According to Pascual-Leone, mental capacity increases from $\mathrm{e}+1$ at 3 years of age to about e +7 at 15 years; where e represents the mental effort or energy required to attend to specific easily understood and remembered questions posed by given tasks and the number represents the maximum number of "schemes" 
that can be successfully coordinated at a given time to solve the task. The Figural Intersection Test developed by Pascual-Leone and Smith has been used to assess the mental capacity of students in various studies (e.g., de Ribaupierre \& Pascual-Leone, 1979; Globerson, 1983; Niaz \& Lawson, 1985; Pascual-Leone, 1970; Pascual-Leone \& Ijaz, 1989).

Scoring. The version of the test used in the present study consists of 32 items. For each item, the subject is asked to mark a point indicating the area of intersection from two through eight overlapping figures. No time limit is given to complete the test. A maximum score of 32 points was possible. A Cronbach's reliability coefficient of .88 was obtained in a sample of Korean secondary school students similar to that of the present study (Ahn, 1995).

Validity. Validity of these instruments as measures of prefrontal lobe activity has been established primarily through multiple reports of prefrontal damage leading to striking deficits in performance on these and similar instruments: inhibiting ability (e.g., Milner, 1963; Weinberger, Berman, \& Illowski, 1988; Weinberger, Berman, \& Zec, 1986); planning ability (e.g., Baker et al., 1996; Black \& Strub, 1976; Fuster, 1989; Luria, 1973; Luria \& Tsvetkova, 1964; Stuss \& Benson, 1986); dissembedding ability (Cicerone, Lasar, \& Shapero 1983; Dempster, 1992; Knight \& Grabowecky, 1995; Kolb \& Whishaw, 1996; Teuber, 1972); working memory (e.g., Baur \& Fuster, 1976; Goldman-Rakic, 1990; McCarthy et al., 1995).

Computation Skills. Computational skills of multiplying, dividing, and the ratio rules used in proportion problems were assessed by use of a researcher-designed test consisting of two multiplying, two dividing, and two ratio rule items. For each of the six items, a correct response was awarded 1 point (Cronbach's alpha $=.75$ ).

\section{General Instructional and Testing Procedures}

As mentioned, subjects who did not use proportional reasoning on the diagnostic Pouring Water Task were randomly assigned to a manipulative or a verbal group for four 30-minute sessions of individual instruction and testing. Subjects in each group were given the same testing-tutoring-testing sequence as following: Pose a cuisenaire rod wall question (test 1), tutor, pose a transfer cuisenaire rod wall question (test 2), tutor, pose a pouring water question (test 3), tutor, pose a transfer pouring water question (test 4), tutor, pose a balance beam question (test 5), tutor, pose a transfer balance beam question (test 6), tutor, pose a coupled gear question (test 7), tutor, pose a transfer coupled gear question (test 8). During this sequence, the manipulative group subjects were allowed to use the manipulatives to check each of their answers (i.e., their predictions).

On the other hand, subjects in the verbal group were not allowed to use the manipulatives to check their answers. Rather, they only received verbal feedback. In other words, they were only shown whether or not they were correct using the $\mathrm{a} / \mathrm{b}=\mathrm{c} / \mathrm{d}$ notation.

\section{Manipulative Group}

Session 1-Cuisenaire Rod Walls. Session 1 involved the use of white and red cuisenaire rods. Initially, the subject constructed a "wall" consisting of two white rods placed on top of one 
red rod (2:1). A row of four red rods was then constructed next to this wall and the subject was asked to predict how many white rods would go with the four red rods to complete the longer wall (test 1). The subject was then allowed to construct the wall to check the prediction. At this point the notation $a / b=c / d(2: 1=x: 4)$ was introduced. The notation was written next to the rods to demonstrate its relationship to the rod walls (tutoring). Hence the session involved manipulative feedback demonstrating proportional relationships as well as the language used to describe these relationships. After this tutoring, the subject was asked to predict how many red rods would be needed on top of nine white rods to complete another wall (test 2) and was allowed to construct the wall to check his/her prediction. Again the notation $a / b=c / d(2: 1=9: x)$ was introduced (more tutoring).

Session 2-Pouring Water. This session used two plastic cylindrical containers with the same vertical scale marked on each, but with differing diameters. Given equal volumes of water for each cylinder, the ratio of the heights of water was 3:2. Subjects observed that water at a height of 4 units in the wide cylinder rose to 6 units when poured into the narrow cylinder. Water was then poured into the wide cylinder to a height of 6 units. The subject was then asked to predict how high the water would rise when these 6 units were poured into the narrow cylinder (test 3). After predicting, the subject poured the water and noted the water rise to 9 units in the narrow cylinder. Then the symbolic notation $a / b=c / d(4: 6=6: x)$ was introduced (tutoring) and the subject was given a transfer task. The transfer task involved pouring water into the narrow cylinder up to the 11th mark and predicting how high the water would rise when poured into the empty wide cylinder (test 4 ). Again the subject poured the water to check the prediction and the notation $a / b=c / d(4: 6=x: 11)$ was introduced (more tutoring).

Session 3-The Balance Beam. A balance beam and hanging weights were used during this session. Initially, the subject was asked to predict where a 5-unit weight should be hung to balance a 10-unit weight which was hung 5 units of length from the fulcrum (test 5). To check the prediction, the subject hung the 5-unit weight on the beam and, if need be, moved the weight incrementally until a balance was achieved.

Following this procedure, the notation $W L=W^{\prime} L^{\prime}\left(10 \_5=5 \_L^{\prime}\right)$ was introduced (tutoring). Then, the subject was given a transfer problem to predict where a 5 -unit weight must be hung to balance two 2-unit weights hung 8 length units from the fulcrum (test 6). After predicting, the subject hung the weight at the predicted location and, if necessary, moved the weight incrementally until a balance was achieved. After achieving the balance, the notation $\mathrm{WL}=\mathrm{W}^{\prime} \mathrm{L}^{\prime}\left(2 \_8=5 \_\mathrm{L}^{\prime}\right)$ was introduced (more tutoring).

Session 4-Coupled Gears. A set of coupled gears was used during this session. The set differed in size ratio of 3:2. Initially, the subject observed a rotation in which 18 rotations of the smaller gear produced 12 rotations of larger gear. Then, the subject was asked the following question: If the smaller gear rotates 16 times, how many times will the larger gear rotate (test 7)? After answering, the subject rotated the smaller gear 16 times while counting the number of times the larger gear rotated (i.e., $102 / 3$ times). After noting this 3:2 ratio, the notation $a / b=c / d$ (i.e., $3 / 2=16 / x$ ) was introduced (tutoring).

After tutoring, the subject observed 12 rotations of the larger gear and was asked: If the larger gear rotates 26 times, how many times would the smaller gear rotate (test 8)? After predicting, the subject rotated the larger gear 26 times and counted the number of rotations of the smaller gear. Again the notation $a / b=c / d$ (i.e., $3 / 2=26 / x$ ) was introduced (more tutoring). 


\section{Verbal Group}

Subjects in the verbal group were individually tutored using the same tasks, procedures, and time duration. They were not, however, allowed to manipulate the materials to test their predicted answers. Only pencil and paper and verbal instructions were used.

\section{Scoring}

Subject responses for each of the eight items were scored on a $0-1$ scale: 0 points for an incorrect use or no attempt to use proportions and 1 point for a successful solution using proportional reasoning. Cronbach's alpha of the 8-item measure was .67.

\section{Results}

\section{Intercorrelations Among Study Variables}

Table 1 shows the Pearson Product-Moment correlations among the study variables. As shown, inhibiting ability, planning ability, mental capacity, and disembedding ability all correlated significantly with the dependent measure of proportional reasoning skill $(r=.43-.47$; $p<.05)$. In addition, inhibiting ability correlated significantly with planning ability and mental capacity $(r=.38$ and .43 , respectively; $p<.05)$ and disembedding ability correlated significantly with mental capacity $(r=.51 ; p<.01)$.

\section{Predicting Proportional Reasoning Skill}

Step-wise multiple regression analysis found that inhibiting ability, disembedding ability, planning ability, and mental capacity together accounted for $45.2 \%$ of the variance in proportional reasoning skill following instruction $(F(5,50)=8.26 ; p<.001)$ (Table 2). Inhibiting ability accounted for the largest percentage $(22.5 \%)$ followed by disembedding ability accounting for $9.0 \%$, planning ability $7.4 \%$, mental capacity $3.8 \%$, and age $2.5 \%$. Respective standardized partial regression coefficients were $.19, .15, .33, .24$, and .17 , which accounted for

Table 1

Pearson Correlation Matrix across study variables

PROPO Inhib. Abl. Plan. Abl. Disem. Abl. Ment. Cap. Age Com. Skill

\begin{tabular}{lllllllll}
\hline PROPO & 1.00 & & & & & & \\
Inhib. Abl. & $0.47^{*}$ & 1.00 & & & & & \\
Plan. Abl. & $0.45^{*}$ & $0.38^{*}$ & 1.00 & & & & \\
Disem. Abl. & $0.43^{*}$ & 0.29 & 0.16 & 1.00 & & & \\
Ment. Cap. & $0.45^{*}$ & $0.43^{*}$ & 0.07 & $0.51^{* *}$ & 1.00 & & \\
Age & 0.11 & 0.05 & 0.14 & 0.16 & 0.04 & 1.00 & \\
Comp. Skill & 0.13 & 0.28 & 0.02 & 0.23 & 0.01 & 0.04 & 1.00 \\
\hline
\end{tabular}

Note. ${ }^{*} p<0.05 .{ }^{* *} p<0.01$. PROPO $=$ the ability to use proportional reasoning strategies; Inhibit. Abl. =inhibiting ability; Plan. Abl.=planning ability; Disem. Abl=disembedding ability; Ment. Cap = mental capacity; Comp. Skill $=$ computation skills. 
Table 2

Regression summary for prediction of the performance on the proportional tasks

\begin{tabular}{lccc}
\hline Predictor Variables & $R$ & $R^{2}$ & Increment of $R^{2}$ \\
\hline Inhib. Abl. & 0.47 & 0.23 & 0.23 \\
Disem. Abl. & 0.56 & 0.32 & 0.09 \\
Plan. Abl. & 0.62 & 0.39 & 0.07 \\
Ment. Cap. & 0.65 & 0.43 & 0.04 \\
Age & 0.67 & 0.45 & 0.02 \\
\hline
\end{tabular}

Note. $N=$ number of subjects; $R=$ regression coefficient.

Dependent Variable: PROPO $N: 56 R: .67 R^{2}: 45$.

$3.6,2.3,10.9,5.8$, and $2.9 \%$ of the unique variance. Computation skill did not significantly predict performance on the proportional reasoning items.

This is not surprising given that the mean score on the test of computation skills was 5.56 out of the maximum of 6.0 points. This indicates that, although scores on the proportional reasoning items varied, the variation was not due to variation in computational skills. Clearly most subjects already knew the ratio rules and were skilled at multiplying and dividing.

\section{Manipulative and Verbal Tutoring}

In spite of no statistically significant difference between verbal and manipulative group subjects in terms of performance on the measures of prefrontal lobe activities, age, and computational skill, the $t$-test results displayed in Table 3 show that the manipulative group significantly outperformed the verbal group on the proportional reasoning tasks $(p<.02)$.

Further, this study found that students in the manipulative group with relatively low prefrontal lobe activity performed at levels very similar to those in the verbal group with relatively high prefrontal lobe activity (Table 4).

\section{Discussion}

As predicted, the prefrontal lobe functions (i.e, inhibiting ability, planning ability, disembedding ability, and mental capacity), correlated significantly with performance on proportional reasoning tasks following instruction (see Tables 1 and 2). Therefore, the hypothesis that prefrontal lobes play a role in proportional reasoning, an aspect of scientific and mathematical reasoning, is supported. This result is consistent with those of previous studies

Table 3

Summary of t-test analysis of performance on proportional reasoning tasks by groups

\begin{tabular}{llllll}
\hline Group & $N$ & Mean & SD & $t$-value & $p$ \\
\hline Manipulative & 30 & 4.13 & 1.91 & 2.45 & 0.017 \\
Verbal & 26 & 3.01 & 1.55 & & \\
\hline
\end{tabular}


Table 4

Cross-comparison of scores on proportional reasoning tasks by group and by prefrontal lobe activity

\begin{tabular}{|c|c|c|}
\hline & Manipulative & Verbal \\
\hline \multicolumn{3}{|c|}{ a. Tutoring group and inhibiting activity } \\
\hline High inhibiting activity & 5.00 & 3.29 \\
\hline Low inhibiting activity & 3.33 & 2.29 \\
\hline \multicolumn{3}{|c|}{ b. Tutoring group and planning activity } \\
\hline High planning activity & 4.73 & 4.00 \\
\hline Low planning activity & 3.45 & 1.89 \\
\hline \multicolumn{3}{|c|}{ c. Tutoring group and disembedding activity } \\
\hline High disembedding activity & 4.88 & 3.67 \\
\hline Low disembedding activity & 3.17 & 2.67 \\
\hline \multicolumn{3}{|c|}{ d. Tutoring group and mental capacity } \\
\hline High mental capacity & 5.00 & 3.17 \\
\hline Low mental capacity & 3.25 & 2.67 \\
\hline
\end{tabular}

(i.e., Dempster, 1991; Harnishfeger \& Bjorklund, 1993; Kwon, 1997; Kwon \& Lawson, 2000). As mentioned by Kwon and Kwon and Lawson, perseveration errors on the Wisconsin Card Sorting Task involve the use of a sorting rule after it is no longer appropriate.

Thus, such errors represent the inefficient deactivation of the task-irrelevant information that was initially, but is no longer, task-relevant. In this sense, inhibiting ability refers to an active process that suppresses task-irrelevant information by removing it from the currently active information group. Viewed this way, this study also supports Kwon and Lawson's hypothesis that successful deployment of reasoning strategies involves both the inhibition of task-irrelevant information as well as the representation of task-relevant information.

In addition, the fact that computation skills did not significantly predict performance on the proportional reasoning tasks (see Tables 1 and 2) supports the claim that the key difference between additive and proportional reasoners in the pouring water task is not the computation skills they possess (Lawson, 1986).

The data in Table 3 show that the manipulative group's overall performance is significantly higher than the verbal tutoring group's. This supports the hypothesis that the physical experience of manipulative tutoring, which engaged visual, auditory, and somatosensory pathways is more effective in the acquisition of proportional skills than verbal tutoring, which engaged only visual and auditory pathways.

Of course, the precise neurological reason(s) for the increased effectiveness of the manipulatives (i.e., visual and somatosensory input) is not clear. But consider the data in Table 4, which shows that students in the manipulative group with relatively low prefrontal lobe activity performed at levels very similar to those in the verbal group with relatively high prefrontal lobe activity. These data are consistent with Grossberg's (1982) claim that unexpected events that might be provoked by the manipulatives (e.g., the student expects water to rise to the 8th mark in the pouring water task but sees it rise to the 9th mark) trigger bursts of nonspecific cognitive arousal which may lead to the discovery and use of a proportional reasoning strategy. Interestingly, the finding that the manipulative group students with relatively high prefrontal 
activity outperformed those in the manipulative group with relatively low activity indicates that the manipulatives help, but do not erase problems associated with low prefrontal activity.

\section{Conclusions and Educational Implications}

In conclusion, the present results provide support for the hypothesis that the maturing prefrontal lobes play a role in proportional reasoning skill as student performance on measures of prefrontal lobe activity predicted responsiveness to instruction. Also, as predicted, manipulative tutoring, which engaged visual, auditory, and somatosensory pathways, provoked significantly better performance than tutoring including only verbal feedback. The use of manipulatives may be more effective because they enable students to actually test their solution strategies and find them inadequate, an element that, according to Grossberg (1982), is necessary to build new strategies.

Therefore, the present results suggest that instruction in proportional reasoning can be effective. But to be optimally effective, instruction should be timed to occur after the plateau period in brain maturation and should make use of manipulatives in which students can generate and test their own strategies, an element of instruction that may be necessary to construct more advanced strategies regardless of maturational level.

This material is based upon research partially supported by the National Science Foundation under grant No. DUE 9453610 and the Korea Science and Engineering Foundation under grain No. KOSEF-19992-501-003-3. Any opinions, findings, and conclusions or recommendations expressed in this publication are those of the authors and do not necessarily reflect the views of the National Science Foundation or the Korea Science and Engineering Foundation.

\section{References}

Ahn, S. (1995). The effects of mental capacity and size of chunk of problem solver and mental demand of problem on science problem solving. Unpublished Doctoral Dissertation, Cheongwon, Chungbuk: Korea National University of Education.

Baker, S.C., Rogers, R.D., Owen, A.M., Frith, C.D., Dolan, R.J., Frackowaik, R.S.J., \& Robbins, T.W. (1996). Neural systems engaged by planning: A PET study of the Tower of London task. Neuropsychologia, 34, 515-526.

Bauer, R.H., \& Fuster, J.M. (1976). Delayed-matching and delayed-response deficit from cooling dorsolateral prefrontal cortex in monkeys. Journal of Comprehensive Physiology and Psychology, 90, 293-302.

Black, F.W., \& Sturb, R.L. (1976). Constructional apraxia in patients with discrete missile wounds of the brain. Cortex, 12, 212-220.

Bruner, J.S. (1965). The course of cognitive growth. The American Psychologist, 19, $26-35$.

Cicerone, K.D., Lazar, R.D., \& Shapiro, W.R. (1983). Effects of frontal lobe lesions on hypothesis sampling during concept formation. Neuropsychologia, 21, 513-524.

de Ribaupierre, A., \& Pascual-Leone, J. (1979). Formal operation and M-power: A neoPiagetian investigation, New Directions for Child Development, 5(1), 1-43.

Dempster, F.N. (1991). Inhibitory processes: A neglected dimension of intelligence, Intelligence, 15, 157-173.

Dempster, F.N. (1992). The rise and fall of the inhibitory mechanism: Toward a unified theory of cognitive development and aging. Developmental Review, 12(1), 45-75. 
Druyan, S. (1997). Effect of the kinesthetic conflict on promoting scientific reasoning. Journal of Research in Science Teaching, 34, 1083-1099.

Dumsha, T.C., Minard, J., \& McWilliams, J.K. (1973). Comparison of two selfadministered field dependency measures. Perceptual and Motor Skills, 36(1), 252-254.

Epstein, H.T. (1974a). Phrenoblysis: Special brain and mind growth periods. I. Human brain and skull development. Developmental Psychology, 7, 207-216.

Epstein, H.T. (1974b). Phrenoblysis: Special brain and mind growth periods. II. Human mental development. Developmental Psychology, 7, 217-224.

Epstein, H.T. (1978). Growth spurts during brain development: Implications for educational policy and practice. In J.S. Chall \& A.F. Mirsky (Eds.), Education and the brain: The seventyseventh yearbook of the National Society for the Study of Education (pp. 343-370). Chicago, IL: University of Chicago Press.

Epstein, H.T. (1986). Stages in human development. Developmental Brain Research, 30, $114-119$.

Fuster, J.M. (1989). The prefrontal cortex: Physiology and neuropsychology of the frontal lobe (2nd ed.). New York: Raven Press.

Globerson, T. (1983). Mental capacity and cognitive functioning. Developmental Psychology, 19, 225-230.

Goldman-Rakic, P.S. (1990). The prefrontal contribution to working memory and conscious experience. Experimental Brain Research, 79, 445-456.

Grossberg, S. (1982). Studies of mind and brain. Dordrecht, Holland: D. Reidel.

Harnishfeger, K.K., \& Bjorklund, D.F. (1993). The ontogeny of inhibition mechanisms: A renewed approach to cognitive development. In M.L. Howe \& R. Pasnak (Eds.), Emerging themes in cognitive development: Foundations, Vol. 1 (pp. 28-49). New York: SpringerVerlag.

Heaton, R.K., Chelune, G.J., Tally, J.L., Kay, G.G., \& Curtiss, G. (1993). Wisconsin Card Sorting Test manual: Revised and expanded. Psychological Assessment Resources, Inc.

Hudspeth, W.J., \& Pribram, K.H. (1990). Stages of brain and cognitive maturation. Journal of Educational Psychology, 82, 881-884.

Inhelder, B., \& Piaget, J. (1958). The growth of logical thinking from childhood to adolescence. New York: Basic Books.

Jeon, Y., \& Jang, H. (1995). The Group Embedded Figure test. Seoul: Korean Testing Center.

Knight, R., \& Grabowecky, M. (1995). Escape from linear time: Prefrontal cortex and conscious experience. In M.S. Gazzaniga (Ed.), The cognitive neuroscience (pp. 1357-1371). Cambridge, MA: MIT Press.

Kolb, B., \& Whishaw, I.Q. (1996). Fundamentals of human neuropsychology (4th ed.). New York: W.H. Freeman.

Krikorian, R., Bartok, J., \& Gay, N. (1994). Tower of London procedure: A standard method and developmental data. Journal of Clinical and Experimental Neuropsychology, 16, $840-850$.

Kwon, Y. (1997). Linking prefrontal lobe functions with reasoning and conceptual change. Unpublished doctoral dissertation. Tempe, AZ: Arizona State University.

Kwon, Y., \& Lawson, A.E. (2000). Linking brain growth with the development of scientific reasoning ability and conceptual change during adolescence. Journal of Research in Science Teaching. 37, 44-62.

Lawson, A.E. (1978). The development and validation of a classroom test of formal reasoning. Journal of Research in Science Teaching, 15, 11-24. 
Lawson, A.E. (1986). A neurological model of sensory-motor problem solving with possible implications for higher-order cognition and instruction. Journal of Research in Science Teaching, 23, 503-522.

Lawson, A.E., \& Wollman, W.T. (1980). Developmental level and learning to solve problems of proportionality in the classroom. School Science and Mathematics, 80, 69-75.

Luria, A.R. (1973). The working brain: An introduction to neuropsychology. New York: Basic Books.

Luria, A.R., \& Tsvetkova, L.S. (1964). The programming of construction activity in local brain injuries. Neuropsychologia, 2, 95-107.

McCarthy, G., Puse, A., Constable, R.T., Krystal, J.H., Gore, J., \& Goldman-Rakic, P.S. (1996). Activation of human prefrontal cortex during spatial and object working memory tasks measured by functional MRI. Cerebral Cortex, 6, 600-611.

Milner, B. (1963). Effects of different brain lesions on card sorting. Archives of Neurology, 9, 90-100.

Niaz, M., \& Lawson, A.E. (1985). Balancing chemical equations: The role of developmental level and mental capacity. Journal of Research in Science Teaching, 22, 41-51.

Pascual-Leone, J. (1970). A mathematical model for the transition rule in Piagetian developmental stages. Acta Psychologica, 32, 301-345.

Pascual-Leone, J., \& Ijaz, H. (1989). Mental capacity testing as a form of intellectual development. In R.J. Samuda, S.L., Kong, J., Cummins, J., Lewis, \& J., Pascual-Leone, Assessment and placement of minority students (pp. 143-171). Toronto: C. J. Hogrefe.

Pascual-Leone, J., \& Smith, J. (1969). The encoding and decoding of symbols by children. Journal of Experimental Child Psychology, 8, 328-355.

Shallice, T. (1982). Specific impairment of planning. In D.E. Broadbent, F.R.S., \& L. Weiskrantz, F.R.S. (Eds.), The neuropsychology of cognitive function: philosophical transactions of the Royal Society of London, Series B, (Vol., 298) (pp. 199-209). London: The Royal Society.

Stein, B.E., \& Meredith, M.A. (1993). The merging of the senses. Cambridge, MA: The MIT Press.

Stuss, D.T., \& Benson, D.F. (1986). The frontal lobes. New York: Raven Press.

Suarez, A., \& Rohnheimer, M. (1974). Lineare funktion. Zurich: Linmat Stiftung.

Teuber, H.L. (1972). Unity and diversity of frontal lobe functions. Acta Neuropsychologica Experimenta, 32, 615-656.

Thatcher, R.W. (1991). Maturation of the human frontal lobes: Physiological basis of staging. Developmental Neuropsychology, 7, 397-419.

Thatcher, R.W., Walker, R.A., \& Giudice, S. (1987). Human cerebral hemispheres develop at different rates and ages. Science, 236, 1110-1113.

Thompson, B., Pitts, M.M., \& Gipe, J.P. (1983). Use of the Group Embedded Figure Test with children. Perceptual and Motor Skills, 57, 199-203.

Witkin, H.A., Moore, C.A., Goodenough, F.R., \& Cox, P.W. (1977). Field-dependent and field-independent cognitive styles and their educational implications. Review of Educational Research, 47, 1-64.

Witkin, H.A., Oltman, P.K., Raskin, E., \& Karp, S.A. (1971). A manual for the Embedded Figure Test. Palo Alto, CA: Counsulting Psychological Press. 